\title{
Shallow S-Wave Velocity Structures in the Western Coastal Plain of Taiwan
}

\author{
Che-Min Lin ${ }^{1}$, Tao-Ming Chang ${ }^{2}$, Yu-Chih Huang ${ }^{1}$, Hsien-Jen Chiang ${ }^{1}$, \\ Chun-Hsiang Kuo ${ }^{1}$, and Kuo-Liang Wen ${ }^{1,2, *}$ \\ ${ }^{1}$ Institute of Geophysics, National Central University, Chung-Li, Taiwan, ROC \\ ${ }^{2}$ National Center for Research on Earthquake Engineering, Taipei, Taiwan, ROC
}

Received 14 May 2007, accepted 10 December 2007

\begin{abstract}
The western coastal plain of Taiwan borders the Western Foothills, which is a fold-and-thrust zone and one of Taiwan's major seismic zones. Earthquakes from the Western Foothills are a frequent cause of disaster in the western coastal plain. In this study, array measurements of microtremors were conducted at seven sites throughout the western coastal plain. At each site, four arrays (S, M, L, and XL arrays) of different sizes were considered. The largest radius of each array ranged from $32 \mathrm{~m}$ to $1 \mathrm{~km}$. The Maximum Likelihood Method of Frequency-Wavenumber (F-K) analyses was used to obtain phase velocity dispersion curves. After the inversion of the dispersion curves with the initial models decided by Genetic Algorithm (GA) searching, shallow S-wave velocity structures for the western coastal plain were estimated.

The S-wave velocity structures were estimated from the surface to a depth of $3 \mathrm{~km}$. Above a depth of $0.4 \mathrm{~km}$, they increased gradually under all sites. The first main interfaces were between 0.4 to $0.75 \mathrm{~km}$ in depth, and the average velocity at all sites increased sharply from 0.808 to $1.289 \mathrm{~km} \mathrm{sec}^{-1}$. This interface seems to be the lower boundary of the thick unconsolidated sediments. The second main interfaces were between 0.9 to $1.75 \mathrm{~km}$ and the average velocity increases from 1.289 to $1.703 \mathrm{~km} \mathrm{sec}^{-1}$. The third main interfaces were between 1.15 to $2.55 \mathrm{~km}$ and the average velocity increased from 1.703 to $2.45 \mathrm{~km} \mathrm{sec}^{-1}$. The depths of the last two main interfaces corresponded to the tops of the Pliocene and upper Miocene formations, respectively, as identified by seismic surveys and exploration wells. Further, the average S-wave velocities of the Plio-Pleistocene, Pliocene, and Miocene formations were estimated in this study. The existence of the Peikang Basement High, which is a prominent barrier in the area between the pre-Miocene and Neogene affects the features of these two interfaces. The depths vary apparently with the distances between the sites and the top of the Peking Basement High; i.e., Penghu Island. Furthermore, the complex structures near the Yichu hinge fault make the S-wave velocities of deeper structures under the Yijhu site higher than those under other sites based on the plane-layer assumption of the F-K analysis.
\end{abstract}

Key words: Array, Microtremor, S-wave velocity, Frequency-Wavenumber (F-K), Genetic algorithm, Peikang basement high, Western coastal plain, Taiwan

Citation: Lin, C. M., T. M. Chang, Y. C. Huang, H. J. Chiang, C. H. Kuo, and K. L. Wen, 2009: Shallow S-wave velocity structures in the western coastal plain of Taiwan. Terr. Atmos. Ocean. Sci., 20, 299-308, doi: 10.3319/TAO.2007.12.10.01(T)

\section{INTRODUCTION}

The western coastal plain of Taiwan is an important economic zone with a large population. This area borders the western side of the western foothills which is a foldand-thrust zone and one of Taiwan's major seismic zones. Earthquakes from the western foothills frequently cause disasters throughout the coastal plain, such as the $1999 \mathrm{M}_{\mathrm{W}} 7.6$

\footnotetext{
* Corresponding author

E-mail:wenkl@earth.ncu.edu.tw
}

Chi-Chi earthquake, the $1998 \mathrm{M}_{\mathrm{L}} 6.2$ Ruey-Li earthquake, and the $1906 \mathrm{M}_{\mathrm{L}} 7.1$ Meishan earthquake.

Strong motion characteristics of the region are required to reduce the potential for loss of life and property from such strong temblors. To this end, it is necessary to conduct site-effect estimations, theoretical simulations of strong motion, and seismic hazard assessments. For these forgoing works, important information about the subsurface structure, especially the shallow S-wave velocity is essen- 
tial. A Rayleigh-wave inversion technique using array records of microtremors has been emphasized as a useful method for obtaining S-wave velocity structures (e.g., Horike 1985; Matsushima and Okada 1990; Sato et al. 1991; Kawase et al. 1998; Satoh et al. 2001a). This method is based on the assumption that microtremors are dominated by Rayleigh waves. Therefore, phase velocities are estimated by the Frequency-Wavenumber (F-K) analysis using vertical components of array records of microtremors. Then, dispersion curves suited to the sites under consideration are solved to invert the S-wave velocity structures. However, the structures obtained by this method are an average within the array site. It is not appropriate to apply this method to sites where the velocity structure varies sharply in the horizontal direction.

Chung and Yeh (1997) used the arrival times of the Rayleigh waves recorded by the dense strong-motion network to obtain average dispersion curves in the period range of 1 to $5 \mathrm{sec}$. Two average S-wave velocity structures (including those of the western coastal plain and the Western Foothills) of the shallow crust in southwestern Taiwan were inverted and confirmed by 2D finite-element strong motion simulations. However, the inverted velocities of the upper layers were slightly higher than those of the 2D models because the inverted velocities represented an average over the paths from the epicenter to the recording stations. Satoh et al. (2001b) conducted array measurements of microtremors at four sites and single-station measurements of microtremors at 48 sites in and around the Taichung basin which lies to the northwest of the western coastal plain and is separated by the Bagua Mountain. The S-wave velocity structure was estimated from array records based on F-K analysis and Rayleigh wave inversions, and the thicknesses of sedimentary layers above the pre-Tertiary bedrock at 48 sites were estimated by fitting the calculated peak and trough frequencies of horizontal-to-vertical spectral ratios of the Rayleigh waves to the observed peak and trough frequencies, assuming the same S-wave velocities estimated by array records.

In this study, array measurements of microtremors were conducted at seven sites throughout the western coastal plain to obtain shallow S-wave velocity structures. Array measurements of field work and data processing are described in the following sections; and the results are then tabulated and discussed with consideration given to previous studies.

\section{REGIONAL GEOLOGY}

The western coastal plain of Taiwan is a low, flat, and almost featureless plain sloping gently to the west. The Quaternary fill covers all the older geologic features which are much more complex.

The Peikang Basement High under the central part of the western coastal plain of Taiwan acts as a prominent barrier and divides the Neogene sedimentary basins into the southern and northern basins, named the Tainan basin and Taihsi basin, respectively (Meng 1968, 1971; Sun 1982). Depositional centers and lithofacies are different in the southern and northern basins. The Peikang Basement High was gradually formed during the pre-Miocene and was regarded as an extension of the continental shelf of the Eurasian plate. The stratigraphic thicknesses of the Neogene formations increase from the Peikang Basement High to the depositional centers of the basins. For example, the total thickness of the Miocene formations may exceed $4000 \mathrm{~m}$, while those in the Peikang Basement High are less than $1000 \mathrm{~m}$. Because the Neogene formations gradually covered the top of this high, the effective barrier of the Peikang Basement High gradually diminished after the upper-Miocene (Shaw 1996). The structural contour map of the top of the Pliocene formations outlined in Fig. 1 exhibits the influences of the Peikang Basement High on the depth of interfaces above that.

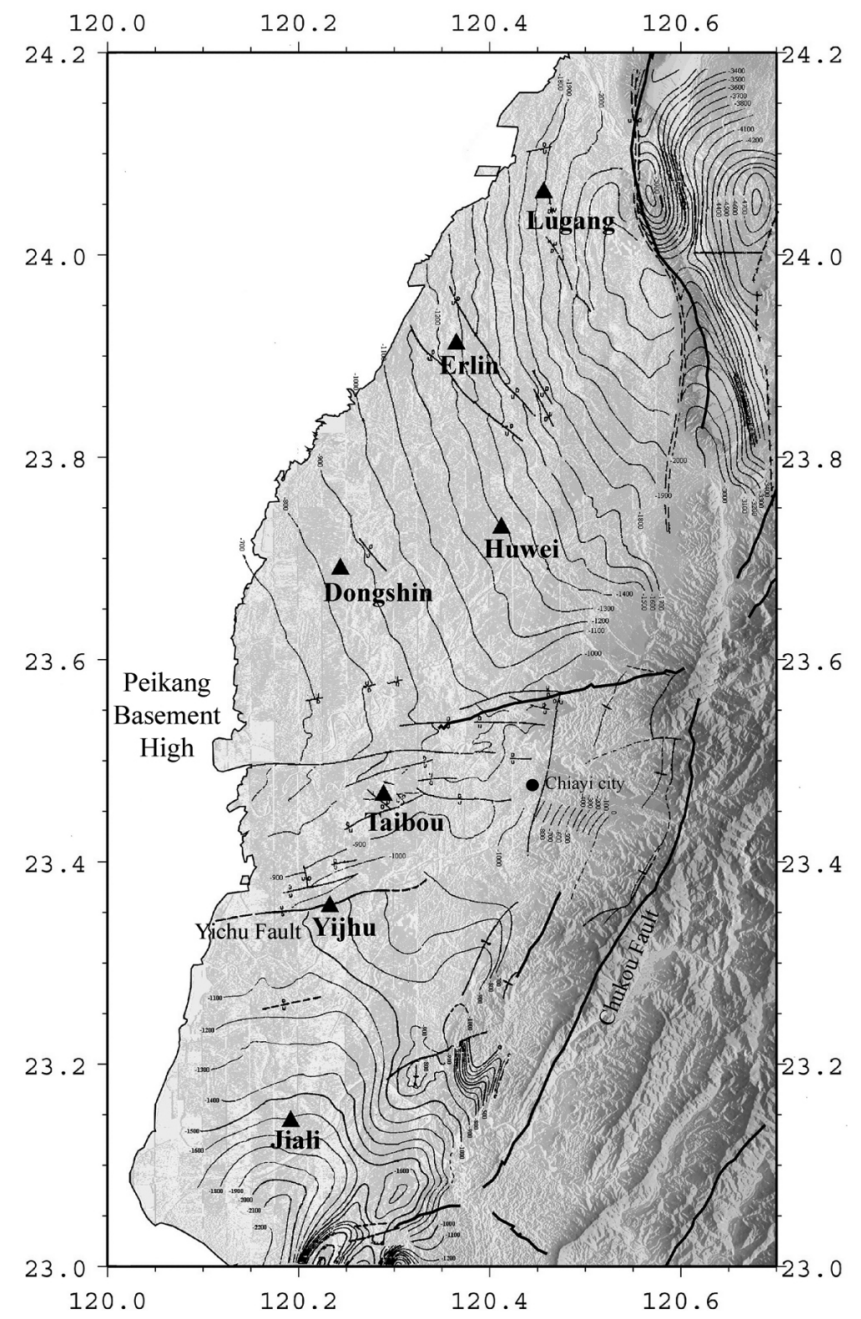

Fig. 1. Distribution of the seven sites for array measurements of microtremors in the western coastal plain of Taiwan. The bold lines are the active faults. The thin lines show the structural contour map of the top of Pliocene formations in depth (meter) (Pan 1967, 1968). 
The center of the Peikang Basement High is the top of the Basement High and close to Penghu Island. It dips $3^{\circ}-5^{\circ}$ eastward and becomes deeply buried at about $4 \mathrm{~km}$ below the ground surface at Chukou in Chiayi. To the east of the Chukou fault, it becomes ambiguous and cannot be identified in seismic profiles (Chou and Yang 1986). The southern boundary of the Basement High is the Yichu hinge fault. Some normal faulting affects the lower part of the sequence near the hinge fault. The Yichu hinge fault formed in early Pliocene and continued faulting until the late Pleistocene and did not extend upward to the surface (Meng 1971; Chow et al. 1988).

\section{ARRAY MEASUREMENTS OF MICRO- TREMORS}

Array measurements of microtremors were conducted at seven sites including Lugang, Erlin, Huwei, Dongshih, Taibao, Yijhu, and Jiali in the western coastal plain of Taiwan (Fig. 1). At each site, four arrays (S, M, L, and XL arrays) of different sizes were considered. The largest radius of each array ranged from $32 \mathrm{~m}$ to $1 \mathrm{~km}$. Every array consisted of ten seismometers including nine distributed over three concentric circles and one common station at the center. Table 1 shows the approximate radiuses and recording lengths for each array. In reality, the radiuses differ slightly from the expected radiuses because of obstructions in field conditions, such as roads, ponds, and buildings. Figure 2 shows an example of the configuration of the $\mathrm{XL}$-array at Lugang. The relative coordinates of seismometers were measured by the total station except for the positions of stations on the outer circles of the XL-arrays that were measured using a Global Positioning System (GPS).

The seven sites for array measurement were chosen over wide and flat farmland to avoid traffic and artificial noise. The seismometers were all buried at depths of about $30 \mathrm{~cm}$ and their internal clocks were synchronized before each measurement. These seismometers are three-component velocity sensors with the flat amplitude in the frequency range 0.07 to $100 \mathrm{~Hz}$. The sampling frequency was $100 \mathrm{~Hz}$. The lengths of the continuous recording time varied between 20 to $360 \mathrm{~min}$, according to the size of the array (Table 1).

\section{DATA PROCESSING}

\subsection{F-K Analysis}

Propagating directions and phase velocities of surface waves for plane-wave propagation can be estimated by F-K analysis. The F-K spectra are usually calculated by two classic methods, the BeamForming Method (BFM) (Lacoss et al. 1969) and the Maximum Likelihood Method (MLM) (Capon 1969), commonly called the conventional method and the high-resolution method, respectively. Because the MLM applies weighting functions known as maximum likelihood filters to suppress other waves of different wavenumbers, it shows a higher resolution than BFM for the estimation of the F-K spectrum when the incoherent noise is much smaller than the power of the propagating waves (Capon 1969; Liaw and McEvilly 1979; Zerva and Zhang 1996). Therefore, MLM F-K analyses were applied in this study.

The observed waveforms of the vertical components were divided into time windows of $20.48 \mathrm{sec}$ in length for the S-array, $40.96 \mathrm{sec}$ for the M-array, and $81.92 \mathrm{sec}$ for the

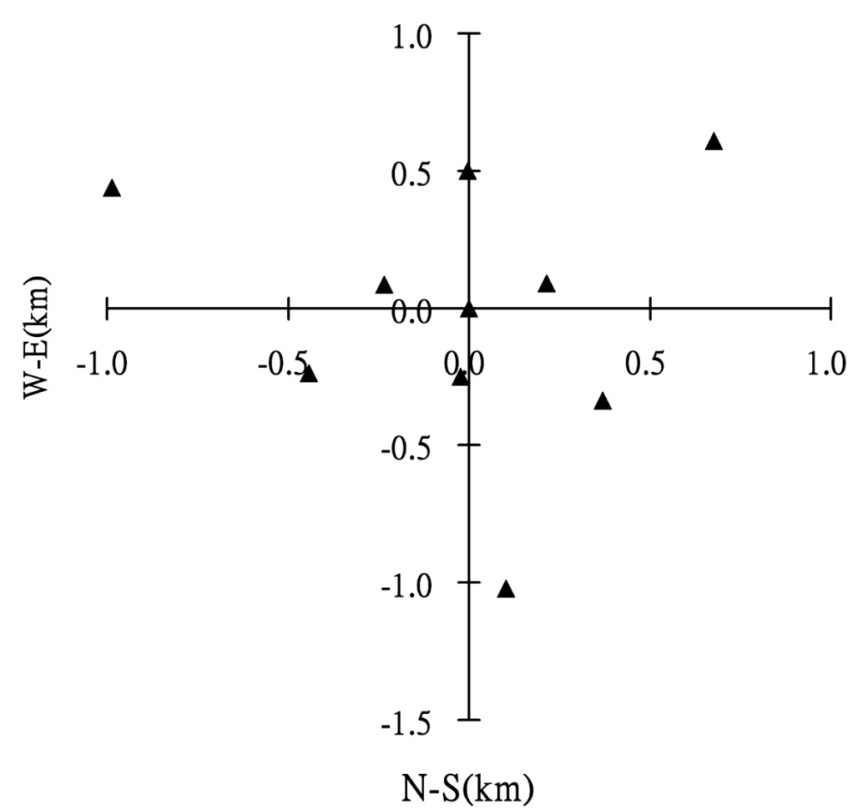

Fig. 2. Array configuration of XL-array at the Lugang site.

Table 1. The approximate radii of arrays with four sizes.

\begin{tabular}{ccccc}
\hline Size & Radius of inner circle & Radius of middle circle & Radius of outer circle & Recording time \\
\hline $\mathrm{S}$ & $8 \mathrm{~m}$ & $16 \mathrm{~m}$ & $32 \mathrm{~m}$ & $20 \mathrm{~min}$ \\
$\mathrm{M}$ & $32 \mathrm{~m}$ & $64 \mathrm{~m}$ & $128 \mathrm{~m}$ & $75 \mathrm{~min}$ \\
$\mathrm{~L}$ & $128 \mathrm{~m}$ & $250 \mathrm{~m}$ & $500 \mathrm{~m}$ & $180 \mathrm{~min}$ \\
$\mathrm{XL}$ & $250 \mathrm{~m}$ & $500 \mathrm{~m}$ & $1000 \mathrm{~m}$ & $360 \mathrm{~min}$ \\
\hline
\end{tabular}


L-array and XL-array by $2 \mathrm{sec}$ moving windows for F-K analyses. The F-K spectra were calculated in $101 \times 101$ grid points in the wavenumber domain for each frequency. Because the resolving frequency of the array measurements is limited by the minimum and maximum station separation of the array, the frequency bands of F-K analyses with some overlap are different between the four different sized arrays. The phase velocity of each frequency was estimated from the wavenumber with a maximum peak in the F-K spectra based on the MLM for all windows. The averages and standard deviations of all windows for each frequency were calculated.

The average phase velocities of S, M, L, and XL arrays at Lugang are shown in Fig. 3. Reasonable and smooth dispersion curves for all sites were obtained based on their average phase velocities. Figure 4 shows the variations of the dispersion curves of all sites. It is apparent that the estimated dispersion curves slightly vary in slope and turn from site to site. The lowest frequencies of the dispersion curves are between 0.15 to $0.25 \mathrm{~Hz}$ and the highest frequencies are between 2 to $6.5 \mathrm{~Hz}$. The differences in reliable frequency bands result from the differences in the signal-to-noise ratios between the seven sites.

\subsection{GA Searching}

Before the inversion of the S-wave velocity structures, we have to decide which initial models dominate the correctness of results for all sites. In this study, we tried to estimate shallow structures that are changeable, and some complex structures, including basement high, folds and faults, under the region. The same and simple initial models of inversions for all sites would be not suitable. Therefore, Genetic Algorithms (GA) combined with the forward modeling of surface-waves (Herrmann 1985) was applied to search for the appropriate initial models. GA searching is a powerful

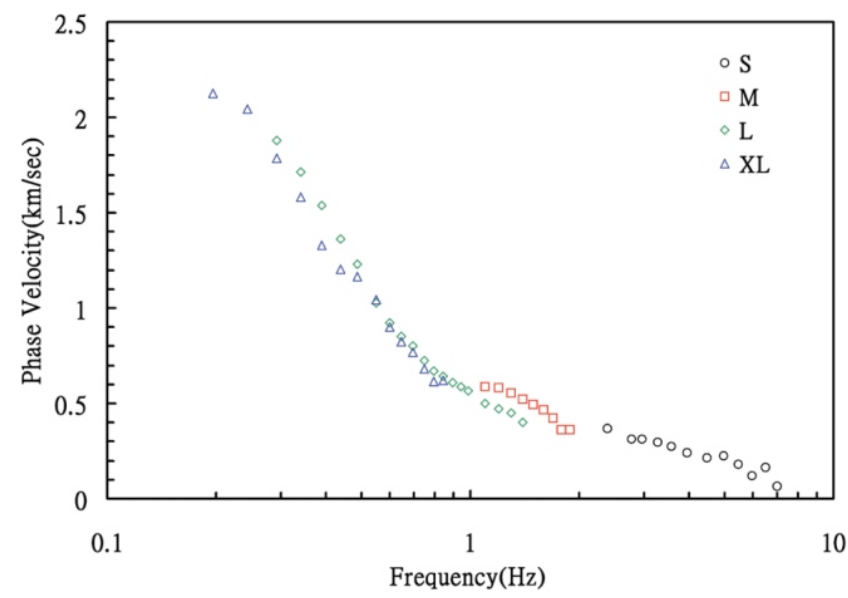

Fig. 3. Average phase velocities of four arrays with different sizes estimated by MLM F-K analyses at the Lugang site. global optimization method. The algorithm consists of selection, crossover, and mutation of individuals in a population; it can search both globally and locally for an optimal solution (Goldberg 1989). GA searching has been used in many seismological applications (Sambridge and Gallagher 1993; Yamanaka and Ishida 1996).

A model with 12 layers covering a half space is assumed for GA searching. The unknowns for the GA searches conducted in this study are the S-wave velocities and the thicknesses of layers. Because we tried searching for all possible interfaces affecting the dispersion curves, the ranges for the velocity and thickness under examination were wide and the 12 layers assumed may have been too many for the number of layers we can estimate. P-wave velocities and densities of layers were determined base on their relation to the $\mathrm{S}$-wave velocities. The full GA process included conducting one hundred GA searches. Each GA search was terminated at the $500^{\text {th }}$ generation. The population size of each generation was fifty. Therefore, the total number of repetitions for forward modeling was 2500000 . The probabilities of crossover, jump mutation, and creep mutation were $0.7,0.05$, and 0.5 , respectively. Our GA searches also included elite selection and tournament selection for enhancing efficiency and avoiding premature local convergence.

In GA searches, a new population is reproduced by selections, crossovers and mutations based on a fitness function for each individual. A fitness function is defined to judge how a model can explain observed data. Individuals with higher fitness have higher probabilities of being reproduced in the next generation. The final results of GA searches are also selected based on the fitness. The misfit function in this study was defined as a root mean square error $E_{i}$ for $i$ th individual by the following equation:

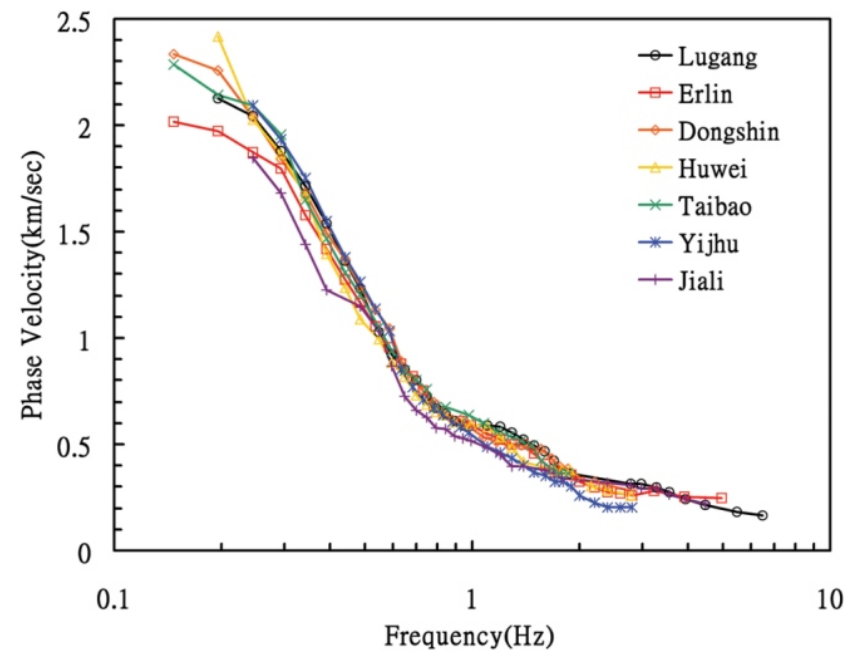

Fig. 4. Comparison of dispersion curves for all seven sites. 
$E_{i}=\sqrt{\frac{1}{n} \sum_{j=1}^{n}\left[U_{O}\left(T_{j}\right)-U_{i C}\left(T_{j}\right)\right]^{2}}$

where $n$ is the number of observed phase velocities; $U_{O}\left(T_{j}\right)$, the observed phase velocity of the jth period, $T_{j}$; and $U_{i C}\left(T_{j}\right)$, the calculated phase velocity of $T_{j}$ of the $i$ th individual. With the misfit function, we defined the fitness function, $f_{i}$, for increasing the efficiencies of searches as

$f_{i}=\left(\frac{1}{1+E_{i}}\right)^{10}$

which obviously ranges from 0 to 1 , with 1 corresponding to the ideal.

Figure 5 shows the best twenty results from the GA searches and the searching ranges at Lugang. The fitness of the best twenty results of all sites are greater than 0.82 . The results of GA searching display the effective convergence of the wide searching ranges for velocities and thickness. The initial inversion model for each site was decided based on the results of GA searching.

\section{GA Search}

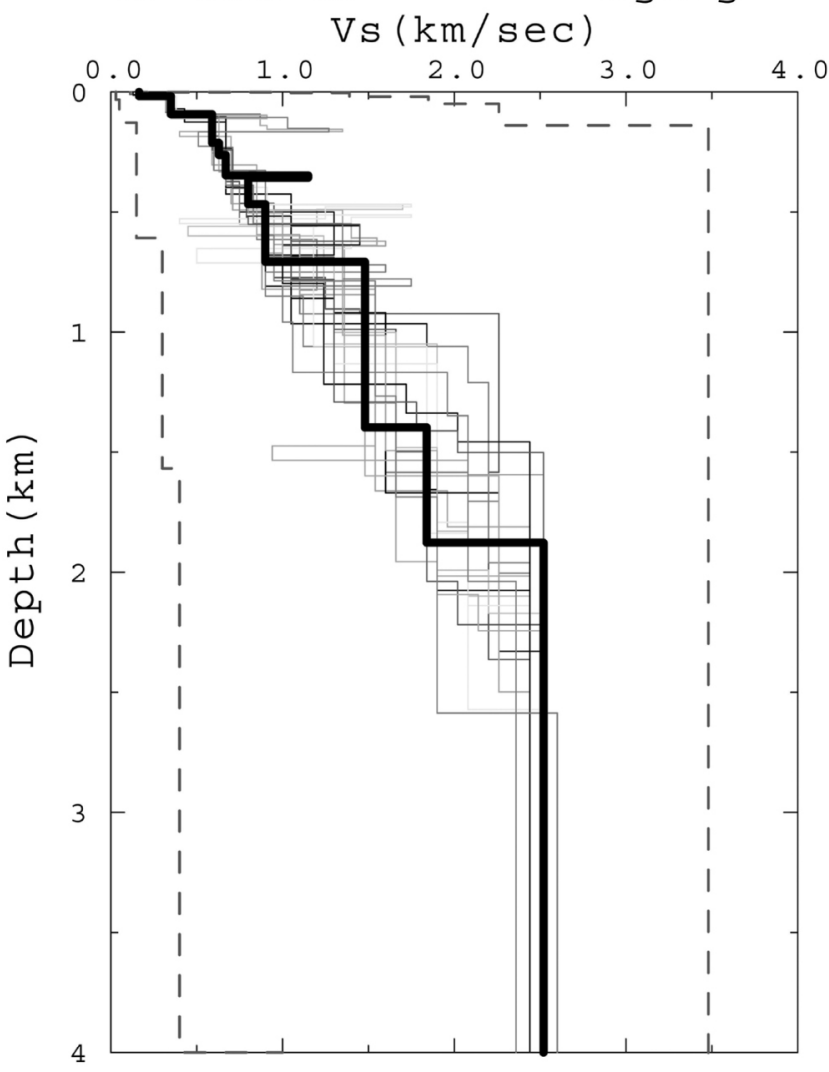

Fig. 5. Best twenty results and the searching ranges (dashed lines) of GA searches for the initial model of inversion for the Lugang site. The bold line indicates the final model with the lowest misfit.

\subsection{Inversion of the Dispersion Curve}

Although GA searching is a robust method and is usually applied to search for optimal solutions, it has some drawbacks. Firstly, there is no information about the resolutions and uncertainties of the results in GA searching. Secondly, the precision is controlled by the two bit strings of the parameters. Each parameter in the searching range was digitized with an $n$-bit binary string of $2^{n}$, which is 32 in this study, so that there were $2^{n}$ variables for each parameter. Longer strings in GA searching produce more precise results, but the convergence time also apparently increases. Therefore, Yamanaka and Ishida (1996) suggested a modified GA inversion method. The method uses GA searching to prepare appropriate initial models for linearized inversions. Inversions after GA searches can improve precision and estimate quality and resolution. Moreover, by this method, the computational time of GA searching is reduced.

The dispersion curves were inverted by stochastic least square inversion (Herrmann 1987) of the fundamental Rayleigh waves to estimate the S-wave velocity structures. In the inversions, the sensitivities of all layers were tested and immaterial and false layers were left out. This step emphasized the major interfaces of velocity profiles and avoided the layers without resolutions of observed dispersion curves. Finally, the best fit model with the lowest variance was accepted as the final result for each site. Figure 6 shows the result of inversion for Lugang, including the S-wave velocity structure and the normalized resolving kernels. The differences between the initial and best-fit models are not large. This proves that the initial model determined by GA searching is close to the real model and facilitates inversion. The resolving kernels indicated that layers up to a depth of $1.9 \mathrm{~km}$ are very well resolved. However, the resolving kernel of the deepest layer is also acceptable.

Figure 7 shows the observed and inverted dispersion curves of the seven sites in the period domain. At all sites, the degree of fit between the observed and inverted dispersion curves is good.

\section{DISCUSSIONS}

Shallow S-wave velocity structures from the surface to about $3 \mathrm{~km}$ in depth were estimated. In the results (Fig. 8), the trends and variations of the velocities at five sites, including Lugang, Erlin, Huwei, Taibao, and Jiali, are alike with variances in depths of the interfaces. However, the results at Dongshih and Yijhu show higher velocities than those at the other sites under about $1 \mathrm{~km}$ in depth. Above a depth of $0.4 \mathrm{~km}$, the S-wave velocities increase gradually at most sites, although those at Taibao are simpler with an apparent transition interface in the near surface because of a lack of phase velocities in the higher frequency band. We identify three main velocity interfaces at these seven sites. 
The first main interfaces are between 0.4 to $0.75 \mathrm{~km}$ in depth, where the average velocity of all sites increases sharply from 0.808 to $1.289 \mathrm{~km} \mathrm{sec}^{-1}$. The shallowest and deepest depths of the first main interfaces are at Jiali and Dongshih, respectively. The second main interfaces are be- tween 0.9 to $1.75 \mathrm{~km}$ in depth, where the average velocity increases from 1.289 to $1.703 \mathrm{~km} \mathrm{sec}^{-1}$. The third main interfaces are between 1.15 to $2.55 \mathrm{~km}$ in depth, where the average velocity increases from 1.703 to $2.45 \mathrm{~km} \mathrm{sec}^{-1}$. The shallowest depths of the last two interfaces are both at Dongshih.

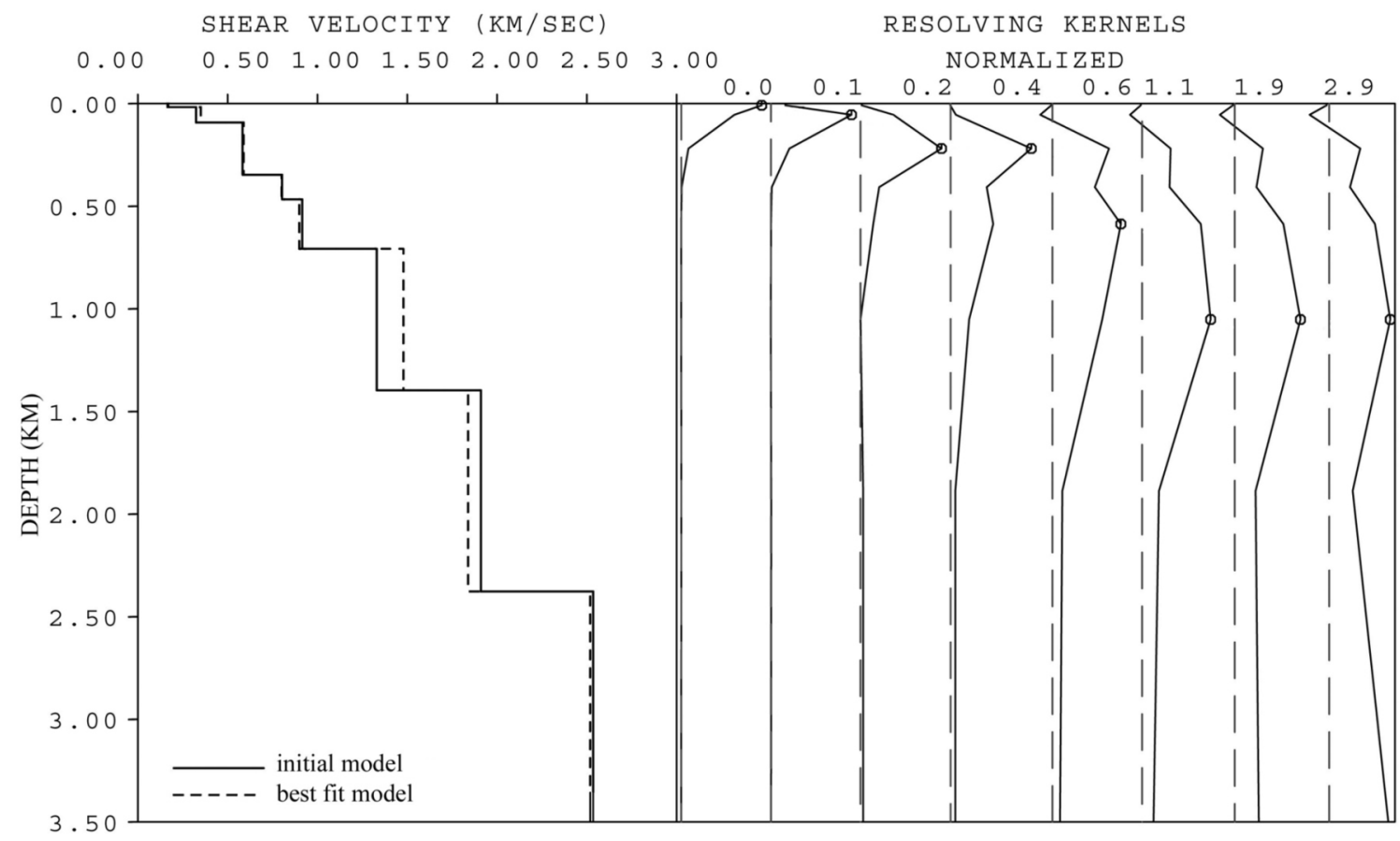

Fig. 6. Result of inversion for the Lugang site. Left figure shows the initial and best fit models of the S-wave velocity structure. Right figure shows the normalized resolving kernels (solid line) at different depth levels indicated by the number at the top of each kernel and the relative baselines (dashed lines).
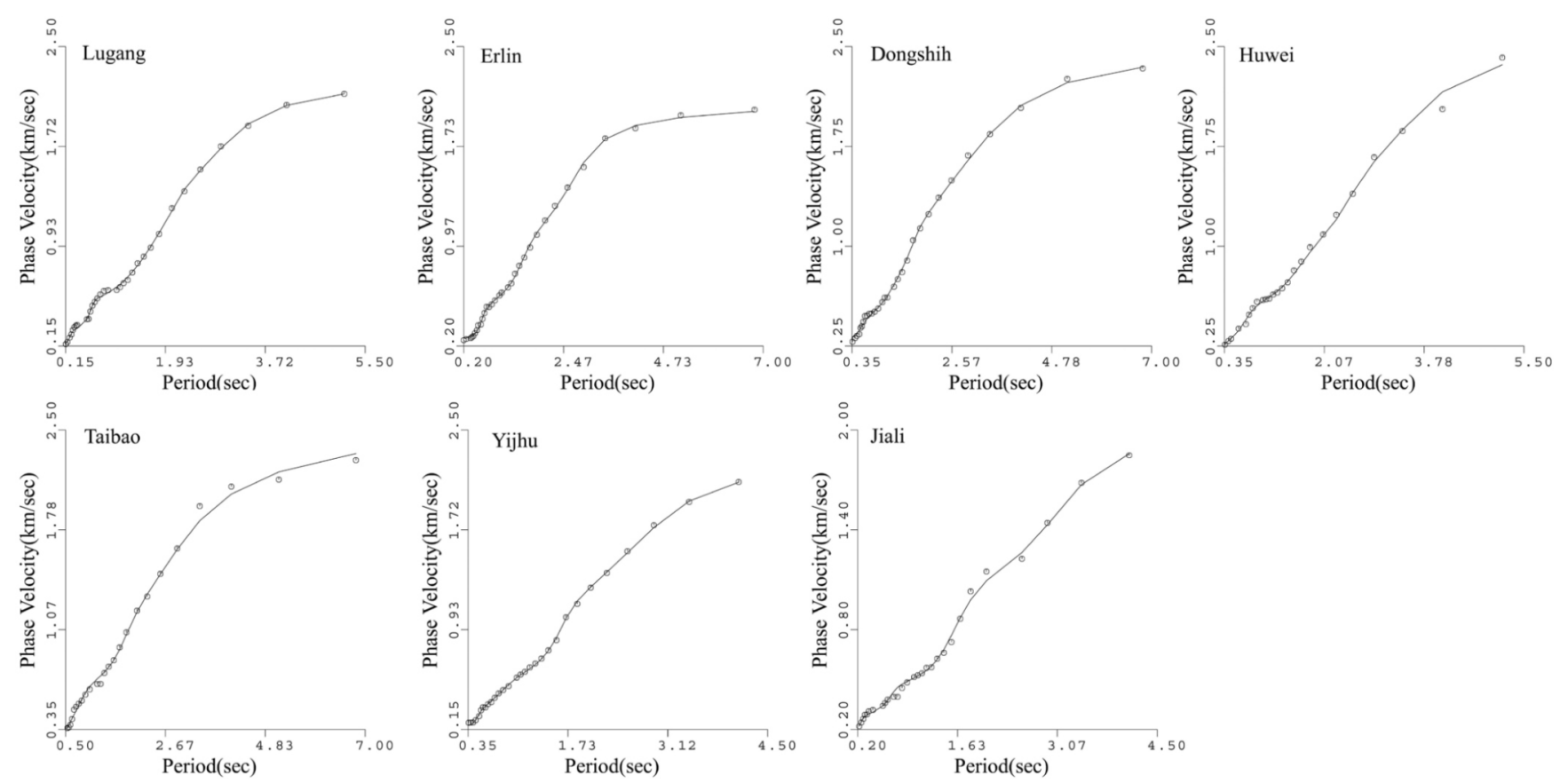

Fig. 7. Observed (black circle) and inverted (line) dispersion curves of all sites in period domain. 

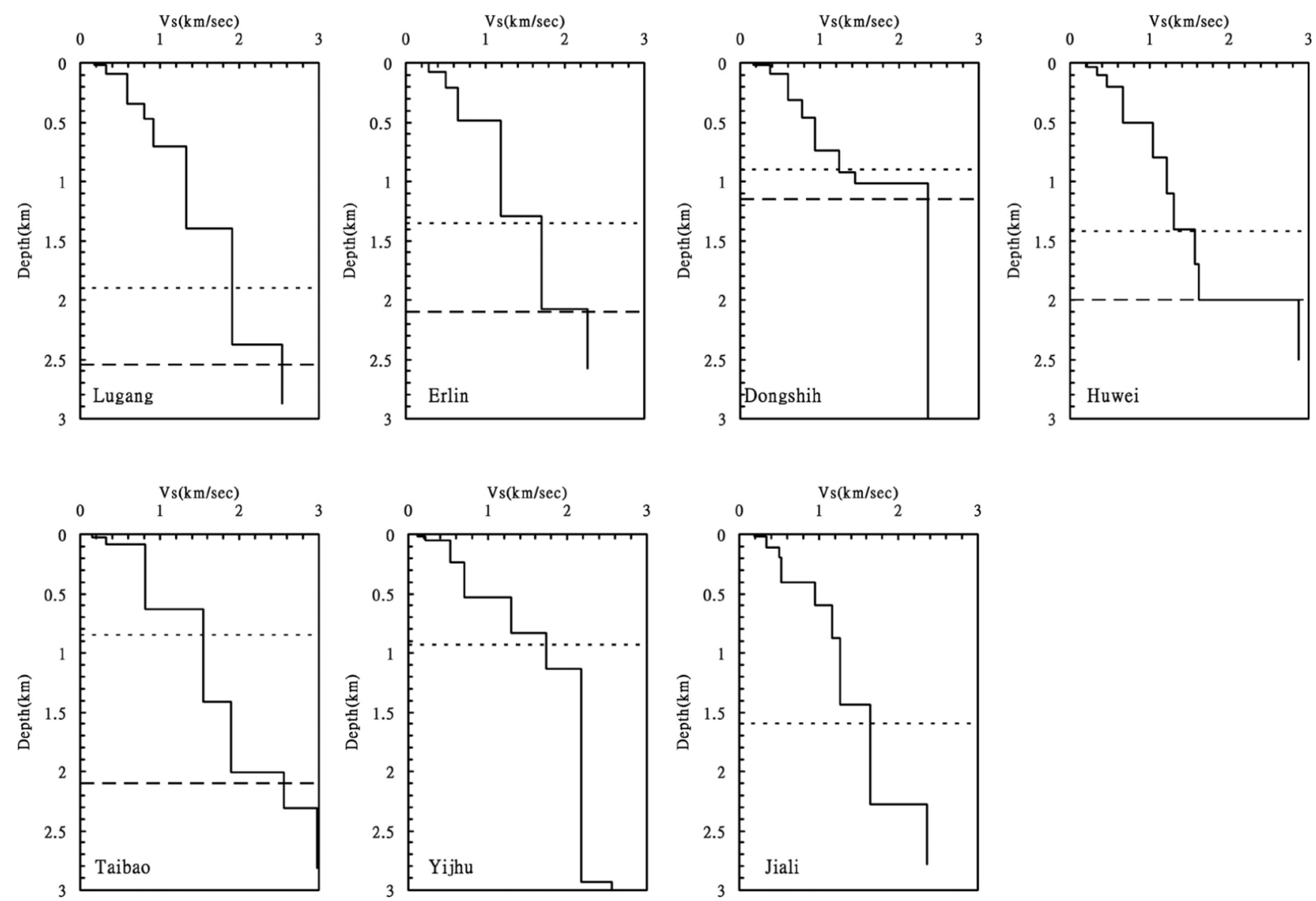

Fig. 8. S-wave velocity structures obtained by inversions of dispersion curves at all sites. The depths of the tops of the Pliocene and Miocene formations are indicated by dotted and dashed lines respectively based on the seismic surveys.

The differences in depth between sites for the same interface get increasingly larger; therefore, the depth of the third main interface at Lugang is deeper than that at Dongshih by $1.4 \mathrm{~km}$.

From previous studies of seismic surveys and exploration wells, the contour maps of the tops of the Pliocene and upper Miocene formations beneath the western coastal plain of Taiwan have been determined. The shallowest parts of these interfaces are close to the top of the Peikang Basement High and dip to the north, east and south (Pan 1967, 1968; Hsiao 1971; Chen 1978). For comparison, the interpolated depths of these interfaces under the seven sites have been drawn in Fig. 8. The dotted lines indicate the depths of the top of the Pliocene formation, and the dashed lines indicate the depth of the top of the Miocene formation. However, the depths of the top of the Miocene formation at Yijhu and Jiali are too deep to be shown on this figure.

The tops of the Pliocene and upper Miocene formations are comparable with the second and third main interfaces of our results, respectively, although with some differences. The Dongshih site which is very close to the top of the Peikang Basement High, has the shallowest depths of the tops of the Pliocene and upper Miocene formations. In addition, at
Dongshih, the thickness of the Pliocene formation is the smallest. The rapid increase of S-wave velocity at Dongshih around $1 \mathrm{~km}$ deep reflects the existence of the two tops. At sites away from the Peikang Basement High, the depths of two tops and the thickness between them increase progressively. The northernmost Lugang site shows the largest depths for the last two interfaces from our estimations, and is apparently underestimated compare with those from seismic data. However, our Erlin and Huwei sites results match the Pliocene and upper Miocene formations tops of seismic data perfectly. At the Taibao site, the third interface agrees with seismic data, but the second interface shows a large difference.

The depth variations of the first main interface for all sites do not show any regularity. One reasonable guess is that this interface could be the boundary for the Plio-Pleistocene formations. Average S-wave velocities have been calculated for comparison with the average P-wave velocities of seismic refraction surveys (Sato et al. 1970). In addition, the $V_{p}$ to $\mathrm{V}_{\mathrm{s}}$ ratios are also calculated and shown in Table 2. This comparison shows that the S-wave velocities of the PlioPleistocene and Pliocene formations in our results are reasonable. But, the S-wave velocities of the Miocene for- 
mation are slightly overestimated.

Furthermore, the Yichu hinge fault which is the southern boundary of the Peikang Basement High crosses through Yijhu (Meng 1971). According to residual gravities and seismic surveying (Hu and Hsu 1988), there are several complex structures, including normal faults and anticlines, near Yijhu. Because of these complex structures, we estimated that the S-wave velocities of deeper structures under Yijhu are apparently higher than those under other sites based on the plane-layer assumption of the F-K analysis.

For the past seven years, some strong motion stations of Taiwan Strong Motion Instrumentation Program (TSMIP) have been bored and measured the top 40 to $70 \mathrm{~m} \mathrm{~V} \mathrm{p}_{\mathrm{p}}$ and $\mathrm{V}_{\mathrm{s}}$ via suspension P-S logging method. We compare our results with those TSMIP stations with distances less than $5 \mathrm{~km}$ from our site as shown on Fig. 9. Although the array results are average layer models, which are not as continual as logging data, the $\mathrm{S}$-wave velocities of the inversions agree with the variances of $V_{p}$ and $V_{s}$ well loggings at most sites. This reflects the correctness of our near-surface inversion results. However, the results at Jiali are apparently overestimated for P-S logging of CHY077. The S-wave velocities of P-S logging are very low, about $0.1 \mathrm{~km} \mathrm{sec}^{-1}$. Because the P-S logging of $\mathrm{CHY} 077$ was performed during the rainy season, discrepancies may result from seasonal variation in the water content of the strata.

Table 2. Comparison between the average S-wave velocities of inversions and average P-wave velocities of seismic surveys in the geologic ages indicated by seismic surveys. The $\mathrm{V}_{\mathrm{p}}$ to $\mathrm{V}_{\mathrm{s}}$ ratios are also calculated and shown.

\begin{tabular}{lccc}
\hline Geologic Age & Average $\mathbf{V}_{\mathbf{S}}$ of Inversion $\left(\mathrm{km} \mathrm{sec}^{-1}\right)$ & Average $\mathbf{V}_{\mathbf{P}}\left(\mathbf{k m ~ s e c}{ }^{-1}\right)$ (Sato et al. 1970) & $\mathbf{V}_{\mathbf{P}} / \mathbf{V}_{\mathbf{S}}$ \\
\hline Plio-Pleistocene & 1.289 & 2.375 & 1.843 \\
Pliocene & 1.703 & 3.195 & 1.876 \\
Miocene & 2.450 & 4.065 & 1.659 \\
\hline
\end{tabular}
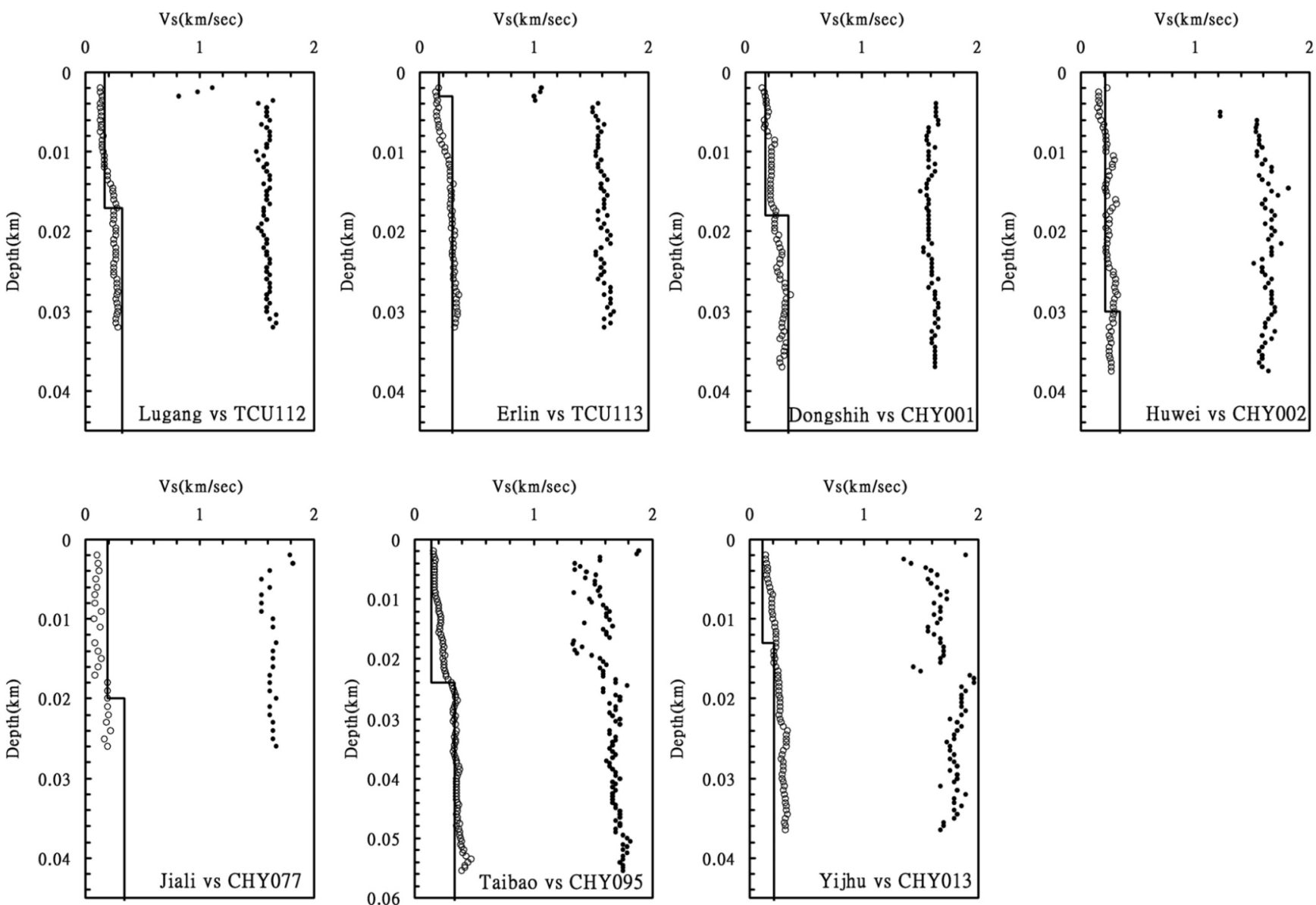

Fig. 9. Comparison between inverted velocities (black lines) of near surface and the P-S logging data (open circles: S-wave velocities; black circles: P-wave velocities) of TSMIP stations within a distance of $5 \mathrm{~km}$ from each study site. 


\section{CONCLUSIONS}

Array measurements of microtremors at seven sites, including Lugang, Erlin, Huwei, Dongshih, Taibao, Yijhu, and Jiali, were conducted in the western coastal plain of Taiwan. Four different array sizes (S, M, L, and XL arrays) ranging from $32 \mathrm{~m}$ to $1 \mathrm{~km}$ were considered at each site. Phase velocities were obtained from the vertical components of the records of MLM F-K analyses to compose the dispersion curves for all sites. The lowest frequencies of dispersion curves were between 0.15 to $0.25 \mathrm{~Hz}$ and the highest frequencies were between 2 to $6.5 \mathrm{~Hz}$. Then, the initial model of inversions for each site was determined based on the results of GA searching combined with forward modeling of surface waves. Subsequently, the dispersion curves were inverted by stochastic least square inversion of the fundamental Rayleigh waves to estimate S-wave velocity structures.

The S-wave velocity structures from the surface to $3 \mathrm{~km}$ in depth were estimated. Three main interfaces with substantial S-wave velocity variations were found, as indicated by the estimated structures. We estimated that the first main interface at a depth of 0.4 to $0.75 \mathrm{~km}$ with a sharp increase in the S-wave velocity from 0.808 to $1.289 \mathrm{~km} \mathrm{sec}^{-1}$ can be considered as the lower boundary of the thick unconsolidated sediments, which are well known in the western coastal plain. The S-wave velocities from the surface to the interface increased gradually at most sites. The depths of the last two main interfaces corresponded to the tops of the Pliocene and upper Miocene formations, respectively, as identified by seismic surveys and exploration wells. Further, the average S-wave velocities of the Plio-Pleistocene, Pliocene, and Miocene formations were also reasonably estimated in this study. The presence of the Peikang Basement High which is a prominent barrier in the area between the pre-Miocene and Neogene, affects the features of these two $\mathrm{S}$-wave velocity interfaces. The depths apparently vary with the distances between the sites and the top of the Peikang Basement High (Penghu Island). The differences in depths between the shallowest and deepest sites were 0.85 and $1.4 \mathrm{~km}$ for the tops of the Pliocene and upper Miocene formations, respectively. The shallowest depths of the last two interfaces were both found at the Dongshih site. However, the depths of the first main interface we identified seem to be unaffected by the Peikang Basement High. These results agree with the inference that the Peikang Basement High was gradually covered and diminished in size during the Neogene. Besides, the S-wave velocities of inversions near the surface agreed with the $V_{p}$ and $V_{s}$ of downhole loggings.

The complex structures near Yichu hinge fault make the deeper structure of the Yijhu site show higher S-wave velocities than those under other sites. This reminded us that the plane-layer assumption of F-K analysis may cause some errors. When the underground structure varied sharply in the horizontal direction, the plane layer model with aver- aged velocities ignored the structure complexity. Therefore, although the average S-wave velocity structure of the Yijhu site can explain the observed dispersion curve, the average structure should be tested carefully before applying it in other studies.

The western coastal plain of Taiwan has been the focus of considerable attention due to its seismic hazard potential. The thick and soft alluviums result in the amplification of seismic waves. The complete and correct shallow S-wave velocity structures of this area obtained from this study should be useful when considering shallow structures for strong motion simulations in the future.

Acknowledgements Well logging data were provided by the National Center for Research on Earthquake Engineering, ROC. This study was supported by the National Science Council, ROC, under the grants No. NSC942116-M-008-005 and NSC95-2625-Z-008-009.

\section{REFERENCES}

Capon, J., 1969: Investigation of long-period noise at the large aperture seismic array. J. Geophys. Res., 74, 3182-3194, doi: 10.1029/JB074i012p03182. [Link]

Chen, J. S., 1978: A comparative study of the refraction and reflection seismic data obtained on the Changhua Plain to the Peikang Shelf, Taiwan. Petrol. Geol. Taiwan, 15, 199-217.

Chou, H. T. and C. Y. Yang, 1986: Characteristics of the sedimentary basins and their potential for oil storage in western Taiwan. Petroleum, 22, 2-25. (in Chinese)

Chow, J., K. M. Yang, and H. M. Chen, 1988: Seismic interpretation of the subsurface structures in the Yichu-Chiali area, southern Taiwan. Petrol. Geol. Taiwan, 24, 60-95.

Chung, J. K. and Y. T. Yen, 1997: Shallow crustal structure from short-period Rayleigh-wave dispersion data in southwestern Taiwan. Bull. Seismol. Soc. Am., 87, 370-382.

Goldberg, D. E., 1989: Genetic algorithms in search, optimization, and machine learning. Addison-Wesley, $412 \mathrm{pp}$.

Herrmann, R. B., 1985: Surface waves in plane layers. Computer program in seismology, 5, Saint Louis University, 116 pp.

Herrmann, R. B., 1987: Surface wave inversion. Computer program in seismology, 4, Saint Louis University, 104 pp.

Horike, M., 1985: Inversion of phase velocity of long-period microtremors to the S-wave-velocity structure down to the basement in urbanized area. J. Phys. Earth, 33, 59-96.

Hsiao, P. T., 1971: Seismic study of the area between the coastal plain and the foothills, Yunlin, Taiwan. Petrol. Geol. Taiwan, 8, 249-263.

Hu, C. C. and H. H. Hsu, 1988: Application of linear inversion to the geophysical data interpretation for petroleum evaluation of the Chiayi coastal plain. Petrol. Geol. Taiwan, 24, 96-122.

Kawase, H., T. Sato, T. Iwata, and K. Irikura, 1998: S-wave velocity structures in the San Fernando and Santa Monica ar- 
eas. Proc. of the $2^{\text {nd }}$ International Symposium on Effects of Surface Geology on Seismic Motions, Tokyo, Japan, 2, 733-740.

Lacoss, R. T., E. J. Kelly, and M. N. Toksöz, 1969: Estimation of seismic noise structure using arrays. Geophysics, 34, 21-38, doi: 10.1190/1.1439995. [Link]

Liaw, A. L. and T. V. McEvilly, 1979: Microseisms in geothermal exploration - studies in Grass Valley, Nevada. Geophysics, 44, 1097-1115, doi: 10.1190/1.1440998. [Link]

Matsushima, T. and H. Okada, 1990: Determination of deep geological structures under urban areas using long-period microtremors. Butsuritansa, 43, 21-33.

Meng, C. Y., 1968: Geologic concepts relating to the petroleum prospects of Taiwan Strait. Petrol. Geol. Taiwan, 6, 1-13.

Meng, C. Y., 1971: A conception of the evolution of the island of Taiwan and its bearing on the development of the western Neogene sedimentary basins. Petrol. Geol. Taiwan, 9, 239-258.

Pan, Y. S., 1967: Interpretation and seismic coordination of the Bouguer gravity anomalies over west-central Taiwan. $P e$ trol. Geol. Taiwan, 5, 99-115.

Pan, Y. S., 1968: Interpretation and seismic coordination of the Bouguer gravity anomalies obtained in southwestern Taiwan. Petrol. Geol. Taiwan, 6, 197-208.

Sambridge, M. and K. Gallagher, 1993: Earthquake hypocenter location using genetic algorithms. Bull. Seismol. Soc. Am., 83, 1467-1491.

Sato, K., C. Y. Meng, J. Suyama, S. Kurihara, S. Kamata, H. Obayashi, E. Inoue, and P. T. Hsiao, 1970: Reports on the seismic refraction survey on land in the western part of Taiwan, Republic of China. Petrol. Geol. Taiwan, 7, 281-293.

Sato, T., H. Kawase, M. Matsui, and S. Kataoka, 1991: Array measurement of high frequency microtremors for underground structure estimation. Proc. of the $4^{\text {th }}$ International Conference on Seismic Zonation, Odawana, Japan, 2, 409-416.

Satoh, T., H. Kawase, and S. Matsushima, 2001a: Estimation of S-wave velocity structures in and around the Sendai basin, Japan, using array records of microtremors. Bull. Seismol. Soc. Am., 91, 206-218, doi: 10.1785/0119990148. [Link]

Satoh, T., H. Kawase, T. Iwata, S. Higashi, T. Sato, K. Irikura, and H. C. Huang, 2001b: S-wave velocity structure of the Taichung basin, Taiwan, estimated from array and singlestation records of microtremors. Bull. Seismol. Soc. Am., 91, 1267-1282, doi: 10.1785/0120000706. [Link]

Shaw, C. L., 1996: Stratigraphic correlation and isopach maps of the western Taiwan basin. Petrol. Geol. Taiwan, 7, 333 360 .

Sun, S. C., 1982: The Tertiary basins of offshore Taiwan. Proc. Second ASCOPT Conference and Exhibition, Manila, Philippine, 126-135.

Yamanaka, H. and H. Ishida, 1996: Application of genetic algorithms to an inversion of surface-wave dispersion data. Bull. Seismol. Soc. Am., 86, 436-444.

Zerva, A. and O. Zhang, 1996: Estimation of signal characteristics in seismic ground motions. Prob. Eng. Mechanics, 11, 229-242, doi: 10.1016/0266-8920(96)00018-5. [Link] 